\title{
Consumption Pattern of Bromadiolone in Presence of Alternative Food by House Mice (Mus musculus) Infesting Poultry Farms
}

\section{-Author(s)}

\section{Aristegui $\mathrm{E}$ \\ Miño MH' \\ Mansilla PR" \\ Guidobono JS' \\ Cueto GR'}

Laboratorio de Ecología de Poblaciones, Instituto de Ecología, Genética y Evolución de Buenos Aires (IEGEBA, UBA-CONICET), Argentina.

" Laboratorio de Ecología Terrestre, Centro Austral de Investigaciones Científicas (CADIC-CONICET), Ushuaia, Argentina.

\section{Mail Address}

Corresponding author e-mail address Evangelina Aristegui

806800 Richmond st West, Toronto, Canadá. M6j3n8

Tel: $\quad(+1)$ 647-838-3274

Email: aristeguievangelina@gmail.com

\section{Eeywords}

Poultry farms, Mus musculus, rodent control rodenticides.

\section{ABSTRACT}

Poultry farms in Central Argentina are often infested by Mus musculus L., despite the regular application of the rodenticide bromadiolone. This failure may be explained by the consumption pattern of mice, which may prefer alternative foods available on the farms to bromadiolone baits. Here we examine the consumption pattern of bromadiolone in the presence of wheat by M. musculus infesting poultry farms compared with the laboratory CF1 mouse strain. Overall, the poultry farm mice had longer survival and lower total food consumption in comparison with the CF1 mice. On the first day of the experiment, rodents from both strains and sexes consumed bromadiolone in the same proportion as wheat. On the second day, female mice of both origins showed a significant decrease in the consumption of bromadiolone, while males kept that proportion constant. Despite the consumption differences between males and females, survival rates were not different. We concluded that rodents from farms behaved as if they had never been in contact with bromadiolone, since they showed the same pattern of poison consumption that the CF1 mice. Females may have associated physical upset with the consumption of bromadiolone, since they decreased its consumption relative to wheat. However, this consumption pattern did not help them to achieve higher survival than males. On poultry farms, the balanced food fed to chickens may function as an alternative food to the poison for rodents. Therefore, we propose that rodenticide should be applied during downtime, when shed are cleaned and there is no chicken feed, which could be used as alternative food.

\section{INTRODUCTION}

Throughout history, the murine rodent Mus musculus L. (house mouse) has been considered a harmful pest worldwide. The damages it causes in rural areas, particularly on livestock and poultry farms, include the consumption and contamination of food, structural damage to building components and equipment, production loss, and spread of diseases and ectoparasites (Berry, 1970; Brooks \& Lynwood, 1978; Timm, 1987; Pratt, 1991). On poultry farms of Central Argentina, $M$. musculus usually achieve worrying densities, and nearly $100 \%$ of the farms continue to be infested, despite the regular application of the anticoagulant rodenticide bromadiolone (Guidobono et al., 2010). Gómez Villafañe et al. (2001) suggested that strategies for controlling rodents based solely on chemical methods are not sufficient to effectively control rodents on poultry farms. The lack of success can be attributed to: (1) permanent recolonization by rodents; (2) the reproductive rate of M. musculus is greater than its mortality; (3) the existence of resistant individuals with ability to maintain a permanent population; and/or (4) rodents consume other food sources instead of bromadiolone baits. 
Consumption Pattern of Bromadiolone in Presence of Alternative Food by House Mice (Mus musculus) Infesting Poultry Farms
A previous study on poultry farms suggests that the populations of $M$. musculus could remain in situ due to their population dynamics (León et al., 2007). It was observed that $M$. musculus on the farms is reproductively active throughout the year, achieves sexual maturity with a month and a half of age, and produces litters with an average of five and seven pups (Miño, 2003). On the other hand, it may also move from other farms, probably using riparian habitats as corridors (León et al., 2010, 2013). More recently, a study on bromadiolone resistance reported that $8 \%$ of $M$. musculus from these farms were resistant (Guidobono et al., 2010).

It is currently unknown whether feeding behaviour strategies may explain the low effectiveness of mouse population control measures applied on poultry farms. Guidobono et al. (2010) proposed that the feeding behaviour of $M$. musculus may have contributed to increase its survival time by a mechanism that potentially allows the metabolic clearance of bromadiolone in $M$. musculus populations present on the farms (Guidobono et al., 2010). The authors suggested that, under rural conditions, the field control program with anticoagulants is less effective than in captivity because there are alternative foods available, which may be preferred to bromadiolone baits. However, this has not been tested yet.

Based on the results of Guidobono et al. (2010), the presented study analysed, under experimental conditions, the consumption pattern of bromadiolone in the presence of an alternative food by wild $M$. musculus individuals that infest poultry farms where bromadiolone is applied periodically. This consumption behaviour was compared with that of laboratory mice of the CF-1 strain not previously exposed to bromadiolone. We predicted that, if poultry farm mice developed bromadiolone aversion, they would consume a smaller proportion of bromadiolone relative to the alternative food than CF1 mice on the first day of the experiment. Furthermore, if laboratory mice are able to associate the physical upset caused by the intake of bromadiolone, its proportional consumption relative to wheat will decrease throughout the experiment.

\section{MATERIALS AND METHODS}

\section{Experimental design}

Two experiments were conducted: one with M. musculus rodents captured on poultry farms (henceforth farm rodents) located in the county of Exaltación de la Cruz, Buenos Aires province, Argentina $\left(34^{\circ} 18^{\prime} \mathrm{S}, 59^{\circ} 14^{\prime} \mathrm{W}\right)$, and the other with mice of the CF-1 strain born in captivity (henceforth CF1 mice).

Farm rodents were captured on five farms where bromadiolone $(0.005 \%)$ had been applied for at least three years. Mice were captured using Sherman live traps for small rodents baited with a mixture of oats, peanuts, and bovine fat. Species, sex, reproductive status, and body measures (length and weight) of each captured rodent were registered. Only $M$. musculus adults were selected for the experiment. Individuals of other species, as well as mice weighing less than $10 \mathrm{~g}$ and pregnant females, were released at capture site.

During the experiment, mice were individually housed in cages $(30 \mathrm{~cm} \times 25 \mathrm{~cm} \times 20 \mathrm{~cm}$ ), equipped with a bottle of water and a feed pan, and were maintained at environmental temperature and natural photoperiod throughout the experiment.

Rodents were randomly assigned to one of the following three experimental groups: Group B, receiving bromadiolone daily $(6 \mathrm{~g})$; Group W (control group), receiving wheat grains daily (6 g); and Group BW, receiving both bromadiolone $(6 \mathrm{~g})$ and wheat grains $(6 \mathrm{~g})$ daily in separate feed pans. All three groups received water ad libitum.

The bromadiolone product used in the experiment was GlexRat ${ }^{\mathrm{TM}}$, the same brand applied on the poultry farms, consisting of red granule baits containing (hydroxy-4'cumarinyl-3')-3-phenyl-3-(bromo-4biphenyl-4')-1-propane-1 at $0.005 \mathrm{~g}$ per $100 \mathrm{~g}$, a bittering agent [denatonium benzoate], colouring, and inert compounds qs). In order to easily distinguish bromadiolone granules from wheat grains, the latter were stained with natural green food colouring based on chlorophyll. M. musculus has poor colour perception (Latham and Mason, 2004) and there is no evidence that it feels attraction for chlorophyll. During the experiment, non-consumed food was carefully collected and weighed daily to evaluate daily consumption. Rodents that died during the experiment were necropsied to confirm the presence of anticoagulation signs caused by bromadiolone consumption, such as massive internal haemorrhages and dark spots in the large intestine.

Before the experiment, mice underwent an acclimatization period of 10 days, during which they never ate an amount of food equal or greater than $6 \mathrm{~g}$ per day. This amount of food was considered ad libitum. During acclimatization, each rodent was fed with wheat grains dyed with red or green food colouring according with the food they were going to receive during the experiment (Group B: red grains; Group W: green grains; Group BW: a mix of green and 
red grains). A total of 76 farm mice were placed for acclimatization; however, 12 escaped and 4 died, and therefore 60 mice were used during the experimental phase, which lasted 10 days (day of placement and nine days of registration of consumption and survival): 9 females and 10 males in Group B, 11 females and 10 males in Group BW, and 10 rodents of each sex in Group W. Mice weight at the beginning of the experiment was $16 \mathrm{~g} \pm 4 \mathrm{~g}$, both for males and females.

The experiment conducted with CF1 mice differed slightly from that with farm rodents. The CF1 mice were 2 months old and included 45 males, with average weight of $27 \mathrm{~g}$, and 45 females with average weight $24 \mathrm{~g}$. Fifteen rodents of each sex were assigned to each experimental food group ( $B, W$ and $B W$ ) and none of them died or escaped during the acclimatization period.

\section{Data analyses}

\section{Consumption}

In order to analyse individual total feed consumption per treatment, we fitted two general linear mixedeffect models (GLMM) to the data using the nlme library of the R Package (R Development Core Team, 2014). The first model included total food consumption as response variable and treatments (Groups $B ; W$ and BW), origin (farm or CF1), sex, and day (1 to $5^{\text {th }}$ day; the following days were not analysed due to the strong unbalance among treatments caused as a result of mortality) as fixed effects. For individuals of Group BW, a second model was fitted, with the proportion of bromadiolone consumption relative to total food offer (with angular transformation) as response variable, and origin (farm or CF1), sex and day ( 1 to $5^{\text {th }}$ day) as fixed effects.

Initially, a model with all possible interactions among fixed factors was fitted to the data, and then the most complex non-significant term was sequentially removed until the simplest significant model that explained most of the deviation was obtained. The significance of each term was assessed by examining the estimated $p$ value of the likelihood ratio statistical test, associated with the change in deviation in the model obtained by the removal of each term (Pinheiro and Bates, 2000). The DGC multiple comparison test (Di Rienzo et al., 2002) was used to detect differences among treatments. Since food consumption was recorded daily for a same individual, a random factor (individuals) was included in both models. Because there was heteroscedasticity in both models, variances were modelled using the varPower function in the R library nlme (Zuur et al., 2009). Additionally, temporal autocorrelation (using the corAR1 function in the $\mathrm{R}$ library $\mathrm{n} / \mathrm{me}$ ) was included in both models. The goodness-of-fit of the models was assessed by visual investigation of residual plots. We used Akaike's information criterion (AIC), and the dimension-consistent Bayesian Information Criterion (BIC), which measure goodness-of-fit and model complexity (Zuur et al., 2009), to identify the model(s) that minimized information loss from a set of candidate models.

\section{Survival}

Survival times among the eight treatments, arising from the combination of origin, sex, and feeding of bromadiolone or bromadiolone and wheat (Groups $B$ and BW, respectively) were compared. The control (group W) was not included in the comparison because the test requires a minimum of one dead animal per treatment. Post-hoc contrasts were performed using Gehan-Wilcoxon test (Gehan, 1965). In accordance with Bonferroni adjustment, a significant level of 0.017 was considered. This value was obtained by dividing the p-value of the survival test by the number of contrasts.

\section{RESULTS}

\section{Consumption}

The mice fed wheat maintained their body weight during the entire experiment, while those receiving bromadiolone and wheat lost $9 \%$ of their body weight, and those fed bromadiolone lost 13\%.

Total food consumption was different between sexes, and such differences changed according to the origin of the animals $\left(F_{\text {Origin } x \text { sex }}: 12.58, p<0.001\right.$, Table 1). Among CF1 mice, males had higher mean daily food intake than females $(4.95 \pm 0.1 \mathrm{~g}$ and $4.31 \pm 0.1$ $g$, respectively; $p<0.05)$. However, no significant differences between farm males and females were recorded $(3.52 \pm 0.12 \mathrm{~g}$ and $3.86 \pm 0.12 \mathrm{~g}$, respectively; p>0.05).

Total consumption pattern (change in food intake over days) differed among treatments ( $F_{\text {Day } \times \text { Treatments: }}$ : 9.93, $p<0.001$, Table 1). The control animals fed wheat (Group W) did not present any variations in the amount of food ingested during the five days analysed (Fig. 1A). Animals fed only bromadiolone (Group B) had a significantly lower consumption on day 1 . Daily consumption increased on days 2 and 3 , reaching the same level as the control group; however, from day 4 , it began to decline again, reaching the minimum on day 5 (Fig. 1A). Meanwhile, animals of Group BW had a mean daily consumption similar to the control group during the first three days, whereas food intake decreased significantly on day 4 , and dropped even lower by day 5 (Fig. 1A). 


\section{Consumption Pattern of Bromadiolone in Presence of Alternative Food by House Mice (Mus musculus) Infesting Poultry Farms}

CF1 mice was higher than that of farm rodents (Fig. 1B). CF1 mice had the highest consumption on day 3, after which consumption decreased, with lowest value recorded on day 5 (Fig. 1B). Consumption by farm rodents did not change during the first four days, but on day 5 , a significant decrease in the average food intake was recorded (Fig. 1B).

For Group BW, the proportion of bromadiolone consumed per day significantly varied depending on the sex of the animal $\left(F_{\text {Sex } x \text { Day }}: 2.72, p=0.031\right.$, Table 2$)$. The proportion of bromadiolone consumed by males did not significantly vary during the five days of the experiment. However, a significant decrease in the proportion of poison consumed by females was recorded from day 2 (Fig. 2). The final model did not include neither the

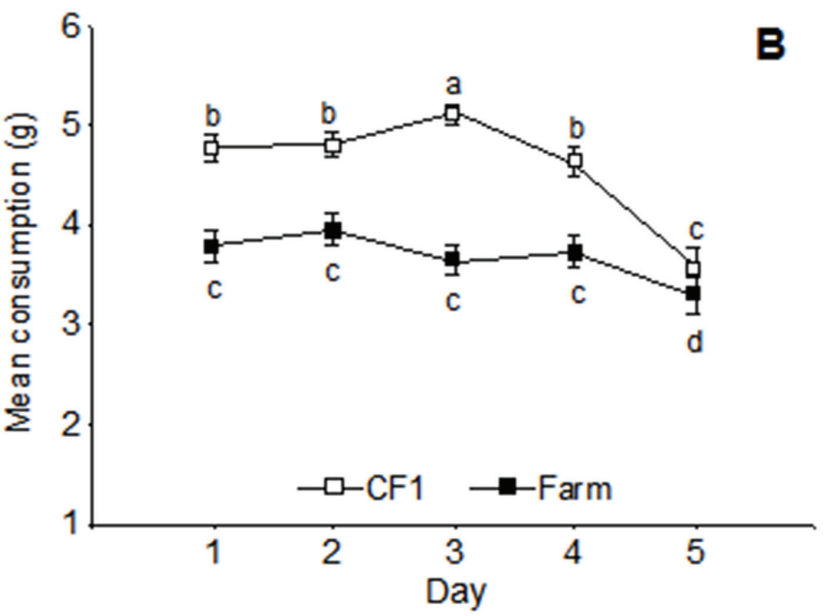

Figure 1 - Mean of the total consumptions by day for (A) Mus musculus fed with wheat $(\mathrm{W})$, bromadiolone $(\mathrm{B})$, or both $(\mathrm{BW})$, by averaging the origin (poultry farms and CF1 mice) and sex (males and females); and (B) M. musculus from both origins averaging the three kinds of food received and the sex. Bars indicate standard error. Different letters indicate significant differences among means $(p<0.05)$.

Table 1 - General Linear Model results for the variation in total daily food consumption of Mus musculus.

\begin{tabular}{lcccc}
\hline Factor & $\begin{array}{c}\text { Numerator } \\
\text { df }\end{array}$ & $\begin{array}{c}\text { Denominator } \\
\text { df }\end{array}$ & F-value & p-value \\
\hline Intercept & 1 & 557 & 3807.29 & $<0.0001$ \\
Day $^{1}$ & 4 & 557 & 11.56 & $<0.0001$ \\
Origin $^{2}$ & 1 & 144 & 44.22 & $<0.0001$ \\
Treatment $^{3}$ & 2 & 144 & 13.02 & $<0.0001$ \\
Sex $^{4}$ & 1 & 144 & 0.71 & 0.4017 \\
Day $^{4}$ Origin & 4 & 557 & 5.69 & 0.0002 \\
Day x Treatment & 8 & 557 & 9.93 & $<0.0001$ \\
Origin x Sex & 1 & 144 & 12.58 & 0.0005 \\
\hline
\end{tabular}

'Day of the experiment (1 to 5 )

${ }^{2}$ Origin of mice (poultry farms or CF-1 laboratory strain)

${ }^{3}$ Kind of food offered (bromadiolone, wheat, or both)

${ }^{4}$ Sex of mice (male or female)

Day, origin, treatment and sex were used as fixed effects.

Furthermore, the consumption pattern also varied according to the origin of rodents ( $F_{\text {Day } x \text { origin }}: 5.69, p<$ 0.001 , Table 1). On each day, mean consumption by origin factor nor its interactions with other factors because they were not statistically significant.

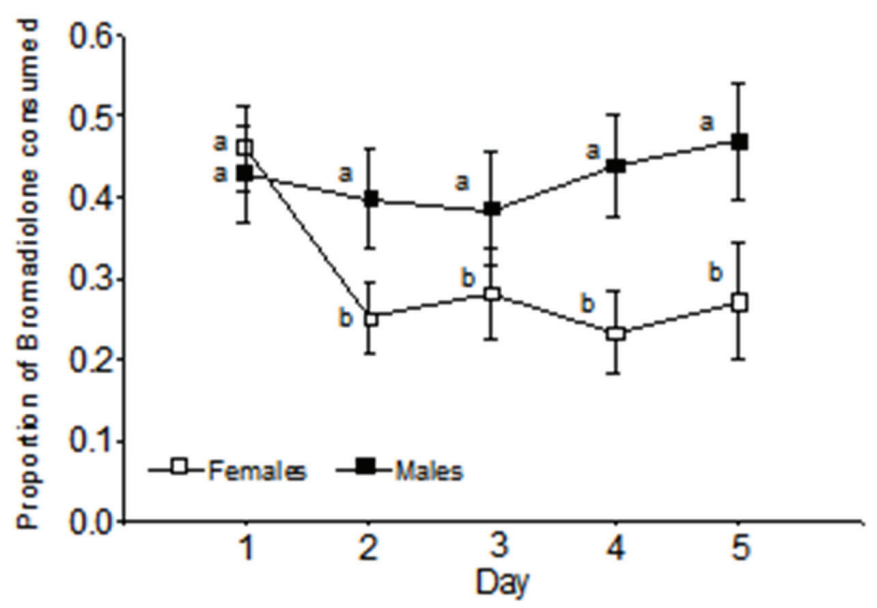

Figure 2 - Bromadiolone proportion relative to the total food ingested by females and males of Mus musculus per day, during the first 5 days of experiment averaging the origin (mice from poultry farms and CF1 mice) and the food they received during the experiment (wheat, bromadiolone or both). Bars indicate standard error. Different letters indicate significant differences among means $(p<0.05)$.

Table 2 - General Linear Model results for the variation in the proportion of poison consumed by individuals of Mus musculus fed with bromadiolone and wheat.

\begin{tabular}{lcccc}
\hline Factor & Numerator df & Denominator df & F-value & p-value \\
\hline Intercept & 1 & 187 & 205.75 & $<0,0001$ \\
Sex $^{1}$ & 1 & 49 & 4.22 & 0.0453 \\
Day $^{2}$ & 4 & 187 & 2.63 & 0.0357 \\
Sex x Day & 4 & 187 & 2.72 & 0.0308 \\
\hline
\end{tabular}

'Sex of mice (male or female)

${ }^{2}$ Origin of mice (poultry farms or CF-1 laboratory strain)

Sex and day were used as fixed effects. Angular transformation was applied to the response variable (proportion of poison consumed).

\section{Survival}

Significant differences were observed among survival times of all treatments $\left(\chi^{2}=56.3, p<0.001\right.$, df $=7, n=100$ ). No rodent in the control group (W) died during the experiment, whereas mice in Group B died significantly earlier than in Group BW (WW $=867, p$ 
Consumption Pattern of Bromadiolone in Presence of Alternative Food by House Mice (Mus musculus) Infesting Poultry Farms
$=0.002, n=100$, Fig. 3). CF1 mice died significantly earlier than farm rodents $(\mathrm{WW}=1828 ; \mathrm{p}<0.001 ; \mathrm{n}=$ 100, Fig. 3). No significant differences were detected between sexes $(W W=179 ; p=0.53 ; n=100)$. All the rodents that died presented bleeding signs.

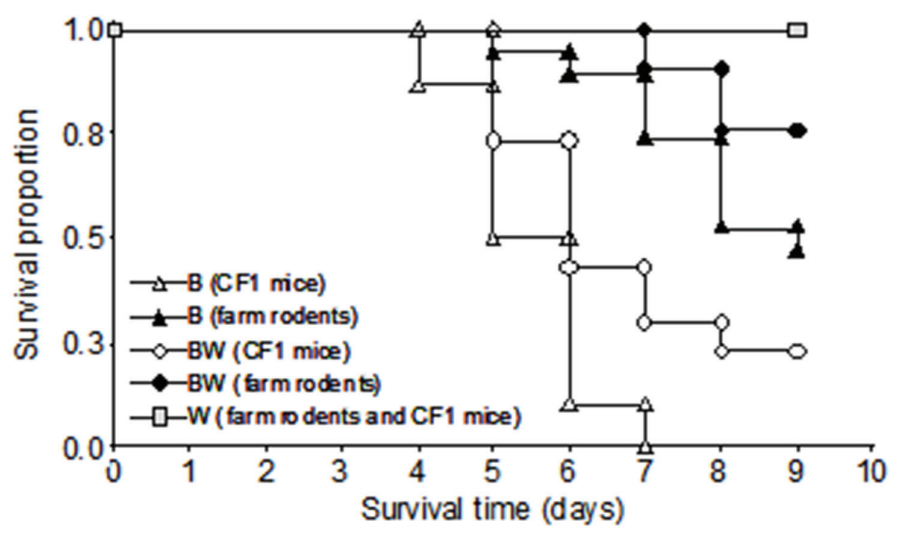

Figure 3 - Survival proportion against time between the beginning and the end of the experiment, in Mus musculus from poultry farms (farm rodents) and laboratory mice of the CF-1 strain (CF1 mice) fed with wheat (W), bromadiolone (B) or both kinds of food (BW). Sexes were pooled because they did not differ significantly.

\section{DISCUSSION}

We designed this experiment to analyse the consumption pattern of bromadiolone by Mus musculus infesting poultry farms in the presence of an alternative food, because we believe that this can help to understand the reason of their persistence in poultry farms despite the periodic application of bromadiolone. We predicted that if the rodents were able to associate physical upset with the intake of bromadiolone, its proportional consumption relative to wheat would decrease throughout the experiment. Our results revealed that this was true for female mice caught on the farms as well as for females of the CF-1 strain. Female mice decreased the proportion of bromadiolone consumption from day 2, and was maintained low for the following days. On the contrary, males of both origins maintained the same proportion of bromadiolone consumption throughout the experiment. However, the different consumption strategies of males and females did not seem to have any effect on survival rates under these experimental conditions, since both sexes showed similar survival curves when fed bromadiolone and wheat baits simultaneously. Other authors, who offered only bromadiolone to rodents, did not find any differences in survival times of males and females either (Guidobono et al., 2010). In contrast, in another study, it was found that females were less susceptible than males to the effects of anticoagulants (Ashton et al., 1987). We believe that these consumption strategy differences between males and females must have some evolutionary advantage for the species. It is possible that the feeding strategy of females in natural situations, such as in poultry farms, is more efficient than in the captive conditions of the present experiment, since the proportion of poison relative to total food offer in our experiment was $50 \%$ higher than that applied on the farms. Further studies on the feeding strategies of male and female mice, offering a wider range of alternative foods or lower poison proportions, are necessary to elucidate whether the strategy of bromadiolone consumption by females is more successful for survival than the strategy of males.

On the other hand, our results did not support the prediction that the mice captured on farms where bromadiolone was being applied would be able to recognize it when they were offered bromadiolone baits for the first time in captivity. In our experiment, both CF1 mice (which had never been exposed to bromadiolone) and farm rodents (caught on farms where bromadiolone was applied) consumed the same proportion of poison baits on the first day of experiment. Therefore, farm rodents behaved naively, as if they had never had contact with bromadiolone. This may be attributed to: (1) the inefficiency of design of the control programme applied on the farms where mice were caught, or 2 ) the fact that farm rodents did not develop aversion to bromadiolone. The reason why the pest control programme failed was not due to poison ineffectiveness, since $100 \%$ of CF1 mice receiving only bromadiolone died. Moreover, bromadiolone is a second-generation anticoagulant, whose effectiveness on M. musculus has been well proven (Meehan, 1978; Redfern \& Gill, 1980; Rowe et al., 1981). The control programme on poultry farms may have failed because mice can easily access chicken feed (located on trays at ground level), and therefore, they would not need to resort to the poison baits to feed.

The other possibility is that farm rodents had contact with bromadiolone on the poultry farms, but they did not develop aversion to it. Actually, it is generally considered that second-generation anticoagulants like bromadiolone do not induce aversion in mice because symptoms appear after a few days of ingesting these poisons. However, there is evidence that some of these anticoagulants can trigger symptoms inducing aversion one day after being ingested (Smith et al., 1994). In this experiment, the latter would reinforce the idea that female $M$. musculus did not have contact with the poison when they were on the poultry farms because 
females from both origins (CF1 and farms) consumed the same proportion of bromadiolone on the first day, and furthermore, both decreased bromadiolone consumption on day 2 .

Mus musculus infesting poultry farms may not develop aversion to bromadiolone for several reasons. Firstly, the attractants of the poisoned baits may not be efficient enough in the presence of chicken food, and to elucidate this, chicken feed should be offered as an alternative food instead of wheat grains. Chicken feed is mainly made of corn. Here, wheat was used to analyse the consumption pattern of bromadiolone in the presence of an alternative food because we wanted to minimize the influence of other variables, such as bait shape and size. As bromadiolone baits are made of wheat grains, the only difference between bromadiolone and the alternative food used was the bromadiolone cover on the baits. Secondly, although in low concentrations, chicken feed contains vitamin $\mathrm{K}_{3}$ (menadione: 1.0-1.5 mg/kg food), which can counteract the effect of anticoagulants (MacNicoll and Gill, 1993; O'Reilly, 1976). Thirdly, rodents infesting poultry farms may be resistant to bromadiolone. As we mentioned before, $8 \%$ of the mice population on the same farms where rodents were sampled in our experiment were shown to be resistant (Guidobono et al., 2010).

The lower survival rate of CF1 mice compared with farm rodents, both when fed only with bromadiolone and bromadiolone and wheat, may be due to the fact that CF1 mice always consumed more food than farm rodents in all three treatments (bromadiolone, wheat or both). The effects of bromadiolone depend on the cumulative dose ingested. Thus, since CF1 mice ingested more food per day, the lethal dose of bromadiolone was possibly achieved earlier than in farm rodents.

In conclusion, the consumption pattern of mice from farms applying rodent control programmes using bromadiolone was not consistent with those expected for mice that develop aversion to that poison, since they presented the same pattern of bromadiolone consumption as CF1 mice. On the other hand, it would seem that females associate bromadiolone with the physical upset caused by intoxication, since they reduced the proportion of bromadiolone consumed, as well as the total consumption. However, this consumption pattern was not reflected in the female survival rates under these experimental conditions.

Finally, these results allow us to recommend some management practices to control $M$. musculus populations on poultry farms. Since the balanced feed fed to chickens is accessible to rodents, it would serve as an alternative food to the poison baits. Therefore, we propose that rodenticides should be applied during down time, when chicks or chickens are not present, feeders are empty, and poultry houses are being cleaned.

\section{ACKNOWLEDGEMENTS}

We want to thank all the farmers who kindly let us work at their farms. We also want to thank Universidad de Buenos Aires (UBACYT X027) and Agencia Nacional de Promoción Científica y Técnica (ANPCYT 33513), Argentina, for funding this study.

\section{REFERENCES}

Ashton AD, Jackson WB, Peters $\mathrm{H}$. Comparative evaluation of LD50 values for various anticoagulant rodenticides. In: Richards CGJ, Ku TY, editors. Control of mammal pests. London: Taylor \& Francis; 1987. p.187-198.

Berry RJ. The natural history of the house mouse. Field Studies 1970;3:219 262.

Brooks JE, Lynwood A. Vertebrate pests: damage on stored foods. In: Mejia $D$, Lewis B, editors. Agro-industries and post-harvest management service. Roma: FAO; 1978.

Di Rienzo JA, Guzmán AW, Casanoves F. A multiple-comparisons method based on the distribution of the root node distance of a binary tree. Journal of Agricultural Biological, and Environmental Statistics 2002;7(2):129-142.

Gehan EA. A generalized Wilcoxon test for comparing arbitrarily singlycensored samples. Biometrika Trust 1965;52(1-2):203-223.

Gómez Villafañe IE, Bilenca DN, Cavia R, Miño MH, Cittadino EA, Busch M. Environmental factors associated with rodent infestations in Argentine poultry farms. British Poultry Science 2001;42(3):300-307.

Guidobono JS, León V, Gómez Villafañe I, Busch M. Bromadiolone susceptibility in wild and laboratory Mus musculus L. (house mice) in Buenos Aires, Argentina. Pest Management Science 2010;66(2):162167

Latham N, Mason G. From house mouse to mouse house: the behavioural biology of free-living Mus musculus and its implications in the laboratory. Applied Animal Behaviour Science 2004;86(3-4):261-289.

León V, Guidobono JS, Busch M. Abundancia de Mus musculus en granjas avícolas: efectos locales vs efectos espaciales. Ecología Austral 2007;17(2):189-198.

León V, Fraschina J, Busch M. Population subdivision of house mouse (Mus musculus) in an agrarian landscape: consequences for control. Canadian Journal of Zoology 2010;88(5):427-435.

León V, Fraschina J, Guidobono JS, Busch M. Habitat use and demography of Mus musculus in a rural landscape of Argentina. Integrative Zoology 2013;8(s1):18-19.

Mac Nicoll AD, Gill JE. Vitamin K3 in feedstuffs: Antidotal effects in captive anticoagulant-resistant rats and mice. Journal of Wildlife Management 1993;57(4):835-841. 
Miño MH. Caracterización de las comunidades de pequeños roedores en granjas avícolas del partido de Exaltación de la Cruz (provincia de Buenos Aires) [thesis]. Buenos Aires (ARG): Universidad de Buenos Aires; 2003.

Meehan AP. Rodenticidal activity of Bromadiolone- a new anticoagulant. Proceedings of the 8th Vertebrate Pest Conference; 1978; Lincoln: University of Nebraska; 1978. p.122-126.

O'Reilly RA. Vitamin K and the oral anticoagulant drugs. Annual Review of Medicine 1976;27(1):245-261.

Pinheiro JC, Bates DM. Mixed-effects models in S and S-PLUS (Statistics and computing). New York: Springer Science \& Business Media; 2000.

Pratt HD. Control of commensal rats and mice. Self study course 3013G, Vector-Borne disease control, CDC manual. Atlanta: Public Health Service; 1991.

R Core Development Team. R: a language and environment for statistical computing. Publishing $\mathrm{R}$ project Web. Vienna: $\mathrm{R}$ Foundation for Statistical Computing; 2014.
Redfern R, Gill JE. Laboratory evaluation of bromadiolone as a rodenticide for use against warfarin-resistant and non-resistant rats and mice. Journal of Hygiene 1980;84(2):263-268

Rowe FP, Plant CJ, Bradfield A. Trials of the anticoagulant rodenticides bromadiolone and difenacoum against the house mouse (Mus musculus L.). Journal of Hygiene 1981;87(2):171 -177.

Smith P, Inglis IR, Cowan DP, Kerins GM, Bull DS. Symptom-dependent taste aversion induced by an anticoagulant rodenticide in the brown rat (Rattus norvegicus). Journal of Comparative Psychology $1994 ; 108(3): 282-290$.

Timm R. Commensal rodents in insulated livestock building. In: Richards CGJ, Ku TY, editors. Control of mammal pests London. New York: Taylor \& Francis; 1987. p. 15-18.

Zuur AF, leno EN, Walker NJ, Saveliev AA, Smith GM. Mixed effects models and extensions in ecology with R. New York: Springer; 2009. 
